INTERNATIONAL JOURNAL OF MULTIDisciplinARY RESEARCH AND ANALYSis

ISSN(print): 2643-9840, ISSN(online): 2643-9875

Volume 04 Issue 10 October 2021

DOI: 10.47191/ijmra/v4-i10-12, Impact Factor: 6.072

Page No.- 1422-1425

\title{
Gender Representation in the Lexical Functional Grammar
}

\author{
Kparou, Hanoukoume Cyril \\ Babcock University, Ilishan Remo, Ogun State
}

\begin{abstract}
Gender marking is a language universal, although some languages have a stronger Gender-marking grammar. The Lexical Functional Grammar (LFG), a linguistic theory, has a set of rules and levels to render for Gender marking. Bornee and developed within the larger framework of the Generative Grammar, the Lexical Functional Grammar has become a standalone autonomous theoretical theory. This paper draws data from French language to present a comprehensive development of Gender-marking analysis within the Lexical Functional Grammar Framework. Fundamentally, the LSG posits for four phrase structures, which are the C-structure representing lexical entries, the F-structure, which deals with the functional information, the A-structure, which structures predicate-argument relationships, and the o-structure, which handles semantic representations. Although the grammatical gender is arrayed all over the four structures, it is mainly presented in this paper as a feature in the lexicon, typically integrated in the C-structure and F-structure mapping..
\end{abstract}

KEYWORDS: Gender-Marking, Lexical Functional Grammar, mapping, Features, Phrase Structure

\section{INTRODUCTION: THEORETICAL FOUNDATIONS OF THE LEXICAL FUNCTIONAL GRAMMAR LFG}

The Lexical Functional Grammar has grown out of Chomsky's Lectures on Government and Binding (1981) alongside the Minimalist Program (MP). Many LFG linguists do not reject Chomsky's assertions on language in whole, especially, his earlier writings that laid the GG principles down. The LFG scholars believe in the innateness of language, and the linguistic analysis as an explanatory exploration of the speaker's knowledge of the language (Asudeh\&Toivonen 2009). Many central questions stipulated by Chomsky (1981) are also relevant in the LFG: What is knowledge of language? What does a speaker do when he speaks? How is language acquired? What is the relationship between language and knowledge (or brain)? What is common to natural languages? What diversifies natural languages?

The LFG is borne of the initiative of Joan Bresnan, a linguist, assisted by the psychologist Ron Kaplan. Their cumulated efforts resulted in a publication in 1982 entitled Lexical-Functional Grammar: A Formal System for Grammatical Representation. In that book and further writings, they posit that language is lexical-based, constraint-based and non-transformational (see also Dalrymple 2009, Bresnan 1995). The LFG rises in the midst and on the fringe of the Transformational Generative Grammar, which posits the first two principles. The fundamental difference is the last assertion: a non-transformational theory of language. According to LFG, no structure derives from another. Each structure is unique and non-representative. Sentences do not derive from one another, a declarative sentence is independent of its interrogative counterpart, and the same is true for the active and passive sentences. "A central idea of Lexical-Functional Grammar is that different kinds of linguistic information are modelled by distinct, simultaneously present grammatical modules, each having its own formal representation" (Asudeh \&Toivonen 2009: 3).

The LFG has preserved the general phrase structure of X-bare theory, one of the core values of the Principles and Parameters, the former version of the Minimalist Program. The general phrase structure is the following:

1)
a. $X P \rightarrow Y P+X^{\prime}$
b. $X^{\prime} \rightarrow X+Z P$

$X P$ is the maximal projection of every phrase, $X^{\prime}$ is the intermediate step of $X$ which is the head. YP is the specifier of the head and ZP is the complement. 


\section{Gender Representation in the Lexical Functional Grammar}

2)

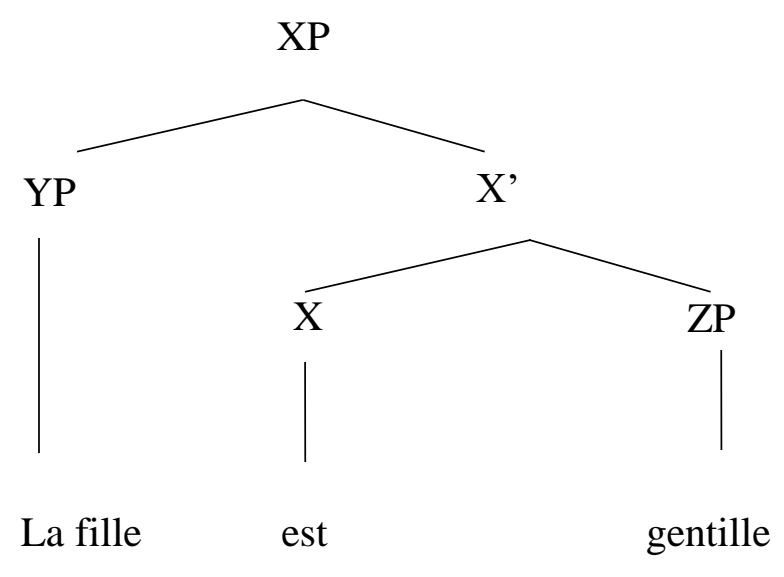

In this structure (2), $\mathrm{X}$ is I (Inflexion), YP is the specifier and ZP is the complement. The head $\mathrm{X}$ and the complement are sister nodes. It is the same for the specifier and the intermediate projection, whereas the maximal projection is the mother node.

French is a typical Gender-marked language, which distinguishes between feminine and masculine lexical elements. Many scholars agree to feature gender morphemes alongside person, number, tenses and case, whenever some of them appear in a particular language (Seljan 2020, Abney 1987, Creissels 2006, Kparou 2018, etc.). In French, the grammatical gender appears alongside number, person and tenses in the lexicon. In the example (2) above, $\mathrm{Y}$ and $\mathrm{Z}$ have elements of Gender.

\section{COMPONENTS OF THE LEXICAL FUNCTIONAL GRAMMAR}

Fundamentally, the LSG posits for four phrase structures: the C-structure, which analyses the lexical entries, the F-structure, which deals with the functional information, the A-structure, which studies the predicate-argument relationships, and the o structure which handles semantic representations.

\section{A. C-structure}

Although four levels of analysis are identified in LFG, it mainly postulates two major components for theoretical representation. The first representation shows lexical items and their inflexional information that is called Constraint Structure (C-Structure). The second one is called Functional Structure (F-Structure) and represents all grammatical relations mapping those lexical items. These two components constitute levels of analysis within the LFG framwork.

The C-Structure contains major information on a specific language, it is where lies most of the information that differentiates one language from another, as all relation changes are lexical (Kaplan \& Bresnan 1982; Asudeh\&Toivonen 2009). The C-Structure is governed by the Lexical Integrity Principle, which states that words are morphologically complete. Thereof comes the assertion that "The syntax is [...] blind to the internal structure of words and sees only their category" (Asudeh \&Toivonen 2009:5). A C-Structure sample can be presented as follows:

1) La fille a fini le devoir (French) "The girl has finished the assignment"

2. [IP [DP La fille [ı a [vp fini le devoir]]]]

$$
\begin{aligned}
I P & \rightarrow D P, I \\
D P & \rightarrow D, N P \\
I & \rightarrow I, V P \\
V P & \rightarrow V, N P \\
D & \rightarrow \text { la, le } \\
N P \rightarrow \text { fille, devoir } & I \rightarrow a \\
V & \rightarrow \text { fini }
\end{aligned}
$$




\section{Gender Representation in the Lexical Functional Grammar}

1)

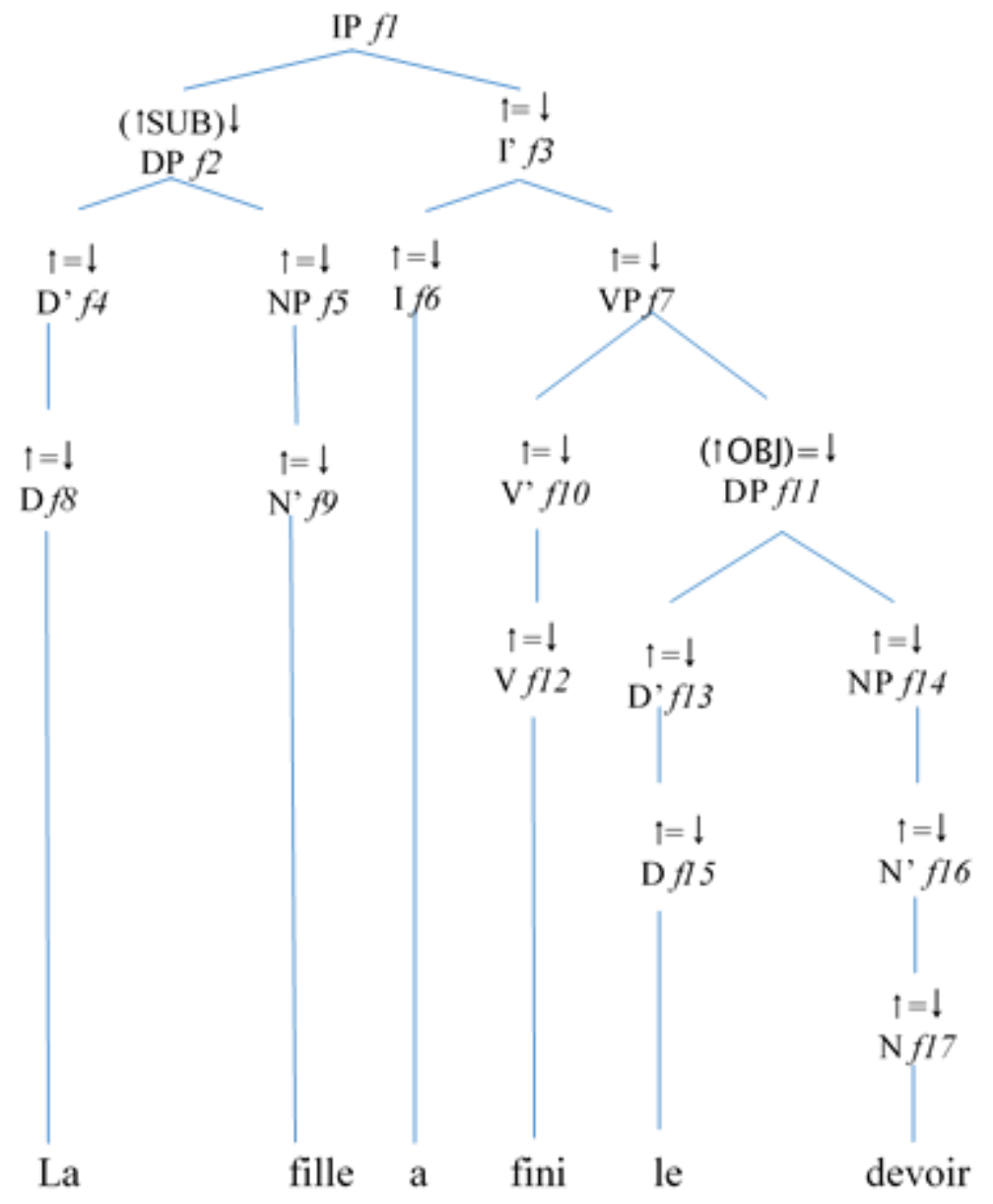

Example (5) shows a C-structure tree or a phrase structure tree, although functions $(f)$ are F-Structure elements. The nature of lexical elements is displayed, but the features are missing, therefore, the grammatical gender is not clearly explained in a Cstructure tree. We would need another level of analysis to explain it.

LFG upholders did not agree on the position and status of NP and DP. According to Dalrymple (2009), the NP dominates DP, which is the specifier. That is not the case for Asudeh \&Toivonen (2009), who posit the DP in a governing node with NP as a complement. Though minor importance is given to that difference in the LFG, I prefer the last one which is similar to the minimalist convention.

\section{A. F-Structure Components}

The C-Structure presents lexical elements in a tree and shows their relationship within a sentence. Functions $(f)$ and metavariables $(\uparrow \& \downarrow)$ are used to show how lexical variables are mapped. The metavariable $(\uparrow)$ means "my mother node" and $(\downarrow)$ means "this node". The equation $(\uparrow=\downarrow)$ means "all my features are my mother' $s$ ".

The F-Structure of the above example is presented in (6) below:

2)

$f 1, f 3, f 6, f 7, f 10, f 12 \quad$ PRED finir $\langle$ SUBJ, OBJ>

TNS Passé Composé

AUX Avoir

SUBJ PRED $f 2, f 4, f 8, f 9$ La fille

NUM SG

PRS 3

GND FEM

OBJ PRED $f 11, f 13, f 14, f 15, f 16, f 17$ le devoir

NUM SG

PRS 3

GND MASC 


\section{Gender Representation in the Lexical Functional Grammar}

The example (6) is an F-structure, which displays some important features of sentence (3). The two DPs are explicated in Fstructure where the GND is used as a feature for gender. The element SUBJ (la fille) is feminine (FEM) while OBJ (le devoir) is masculine (MASC).

\section{CONCLUSIONS}

The Lexical Functional Grammar has two fundamental levels of analysis, which are the C-Structure and the F-structure. Considering the French language as an example of a grammatically gender-marked language, we wondered which level of the LFG considers the gender. The analysis showed that, the C-structure, although aimed at analyzing elements of the lexicon, does not allow one to account for gender. The grammatical gender is rather analyzed at the level of F-structure.

\section{REFERENCES}

1) Asudeh, Ash\& Ida Toivonen. 2009. Lexical Functional Grammar. To appear in Bernd Heine and HeikoNarrog, eds., The Oxford Handbook of Linguistic Analysis. Oxford: Oxford University Press.

2) Bresnan, Joan. 1995. Linear Order, Syntactic Rank, and Empty Categories: On Weak Crossover. In Dalrymple et al (eds). 1995, 241-274.

3) Carnie, Andrew. 2011. Syntax: a Generative Introduction. Blackwell Publishing.

4) Chomsky, Noam. 2000. Minimalist inquiries: the framework, Step by step: essays on minimalist syntax in honor of Howard Lasnik. Cambridge, Massechusetts: MIT Press. Pp. 89-155.

5) Chomsky, Noam. 1995. The Minimalist Program. Cambridge, Massachusetts: MIT Press.

6) Chomsky, Noam. 1981. Lectures on Government and Binding. Dordrecht: Foris.

7) Dalrymple, Mary. 2009. Lexical Functional Grammar.Publication of the Centre for Linguistics and Philology, Oxford University.

8) Falk, Yehuda. 2001. Lexical Functional Grammar. CSIL Publications.

9) Galasso, Joseph. 2003. Analysing English Grammar: An Introduction To Feature Theory. http://www.csun.edu/ galasso.

10) Hockett, Charles. 1960. The Origin of Speech. Scientific American 203, 89-97.

11) Kaplan, Ronald, \& Joan Bresnan. 1982. Lexical-Functional Grammar: A Formal System forGrammatical Representation. In Bresnan (ed.)1982b, 173-281.

12) Kayne, Richard. 1984. Connectedness and Binary Branching. Dordrecht:Foris

13) Lasnik, Howard. 2002. The Minimalist Program in Syntax, Trends in Cognitive Sciences, Vol.6No.10 October 2002.

14) Radford, Andrew. 2006. The Minimalist Program Revised. Cambridge University Press.

15) Wu, Tong. 2011. La relativisation prénominale. Thèse de Doctorat, Université Paris III. 